\title{
Parental Involvement in Children's Mathematics Learning Before and During the Period of the COVID-19
}

\author{
Rita Panaoura \\ Department of Education, Frederick University, Nicosia, Cyprus \\ Email: pre.pm@frederick.ac.cy
}

Received: 22 July 2020; Revised: 5 November 2020; Accepted: 5 November 2020

\begin{abstract}
The pandemic of coronavirus disease 2019 (COVID-19) has led to sudden and unexpected circumstances in education for all the involved people (pupils, teachers, education policymakers, parents). International organizations have paid attention to their responses in crises by using alternative modes of teaching. The typical teaching methods had to be replaced by e-learning processes and all the participants needed to adjust themselves and adapt innovative methods. Most studies concentrated on teachers' and students' difficulties, barriers and new challenges. However, a different role was given to parents as well, especially in the case of primary and the first grades of secondary education, as they were asked to facilitate their children to use the e-learning processes and support them during the learning process. The present study examined the change of parental involvement during the pandemic in comparison to the previous situation in the case of mathematical subject. A questionnaire was constructed and administered to parents from Cyprus at the first days of the school year 2019-2020 in order to examine their beliefs and self-efficacy beliefs about their parental role and involvement during homework at their children's mathematical understanding and the development of their children's perseverance strategies during mathematical problem solving. The same questionnaire was administered to them at the end of the e-learning teaching processes in May 2020, after they had alternative experiences in order to identify any differences at their respective beliefs. Only the sample of parents who took part at both phases of the study was used for the comparative analyses. Results indicated that parents, especially in primary education, had the willingness to support their children's learning under the different teaching and learning processes; however they needed training in order to develop appropriate knowledge, relevant experiences, positive beliefs and selfefficacy beliefs.
\end{abstract}

Keywords: parental involvement, mathematics learning, COVID-19

\section{Introduction}

Classroom instruction is accepted as a central component for understanding the dynamic processes and the organization of students' mathematical thinking and learning (Cai, 2004). This is the normal situation where all the studies are conducted in order to examine the influence and interrelations of the teaching and learning variables. However, there are rare and unusual situations during which the teaching and learning roles change and all the participants have to adjust themselves to new situations. The recent pandemic of COVID-19 led to the interruption of the normal and typical teaching processes at schools for more than two months. According to UNESCO (2020), schools

Copyright (C2020 Rita Panaoura

DOI: https://doi.org/10.37256/ser.212021547

This is an open-access article distributed under a CC BY license

(Creative Commons Attribution 4.0 International License)

https://creativecommons.org/licenses/by/4.0/ 
in 191 countries were in lockdown and 1.5 billion learners were influenced. Governments implemented measures to limit the number of people in public places and schools and they had to handle the situation in order to offer alternative teaching and learning processes in the cases that were possible.

The e-learning processes which were adapted by the educational systems included synchronous and asynchronous teaching processes. Different tools and platforms were used in order to provide the learning materials to students with the contribution of their parents in order to be the mediator, in many cases, between the teacher and their child. In the educational system of Cyprus, in primary education parents were asked to print homework which was sent through e-mail or the school website, to deliver it to their children, to give explanations if necessary, to create passwords and to help their children take part at synchronous online meetings. The parental involvement at the whole teaching and learning process was intense and probably different in comparison to the previous experiences of normality. Their experiences probably influenced their beliefs and self-efficacy beliefs about their role.

The domain of parental involvement and contribution had been examined in many studies in the last decades in relation to children's academic achievements. In general, increasing children's academic performance and achievements is the major goal at all the levels of education and the parents are considered as one of the major influencing factors. Many studies examined the parental involvement during their children's school life (e.g. Patall et al., 2008; Rosario, Nunez et al., 2018). Parental involvement, especially in the case of primary education, is desirable. This involvement has been associated with a number of positive outcomes (Gomes, 2015) in respect to academic performance, socialization and coping students' behavior. In the case of mathematics, there are teachers who propose suggestions to parents on how to handle their children's difficulties during their homework in order to develop their self-regulatory performance and their perseverance in working with mathematical tasks (Panaoura, 2017).

The present study examined this parental involvement at a different framework based on their beliefs and selfefficacy beliefs about their role and contribution. The data before the pandemic of COVID-19 were collected for a different purpose and the experimental design changed due to the understanding of the difficulties teachers and parents faced during the pandemic and the necessity to examine the derived changes in their role. Differences in respect to sex (only one of the two parents participated in the study) and their children's educational level were examined (primary and secondary education). The major part of the study was developed few months before the pandemic of the coronavirus COVID 19. After the virus' spreading internationally and the significant changes to the typical teaching processes which were replaced by the e-learning processes, we had examined in comparison and by using quantitative and qualitative methods the changes in parents' beliefs and self-efficacy beliefs about their involvement which derived by their recent experiences. Two research questions were posed: (i) Which were parents' beliefs and self-efficacy beliefs about their involvement in mathematical learning before and after the pandemic? (ii) Which was the impact of parents' sex and their children's level of education (primary or secondary) on their beliefs and self-efficacy beliefs about their role in learning involvement? The comparison on parents' beliefs and self-efficacy beliefs in respect to the sex is significant as there are not any relevant data in Cyprus, a conservative society, where in most cases, the mother works outside and she has at the same time the major responsibility about children's care and education. The comparison between the primary and secondary education is based on the observed gap in respect to the teaching and learning methods used at the two educational levels. The emphasis on mathematics was based on two major reasons: (i) According to the official Curriculum, there are two major courses which are taught to students every day: the Greek language and Mathematics, (ii) Many students face difficulties in Mathematics and at previous studies we had examined the parental roles on developing students' perseverance during the mathematical problem solving, through the homework and the everyday activities.

\section{Literature review}

\subsection{Parental involvement in mathematics learning}

Different studies reveal an association between parental involvement and academic achievement. Parental involvement refers to the situation where parents are directly involved in the education of their children. However parental involvement has too many different dimensions such as the perception of support, organization, interest in educational process, expectations, school relationship, time for support with homework (Veas et al., 2018). Researchers 
distinguish two main types of parental involvement. The first one concentrates on what parents do at home in order to strengthen their own children's education (Nguon, 2012) and the second one on their involvement with activities organized at schools, such as meetings with the teachers, school events and parental federation (Sibley \& Dearing, 2014). Usually, through school websites, parents become aware of specific activities and topics in which their child is involved (Olmstead, 2013). In few cases, teachers use the website for communication with parents. Gonzalez-DeHass (2016) examines strategies for developing involvement activities in an environment of respectful dialogue between home and school. Fernandez-Alonso et al. (2017) examined the relationship between the styles of parental involvement and their academic performance. Results indicated that students with lower academic results have parents characterized by a more controlling style. Additionally, parents of students who have greater learning difficulties in primary education tend to indicate more controlling behavior in secondary education. Gomes (2015) underlines the benefits of parental involvement: (a) parents understand how and what children learn at school, (b) they realize their children's abilities. Although parental involvement in children's homework takes many forms, the children's achievements at primary education are influenced by the quality and not the quantity of involvement (Orkin et al., 2017).

Boonka et al. (2018) present a literature review about the relationship between parental involvement and students' academic achievement by using a meta-analysis of 75 published studies the last 15 years. As it is expected, studies have found positive relations, negative relations and a lack of relations between parental involvement and student achievement. Silinskas and Kikas (2019) confirmed the existence of mixed results in respect to the research of efficiency of parental involvement in homework on children's academic performance. Parental support which leads to create the appropriate learning environment seems to have a positive impact on students' academic achievement (Sheldon \& Epstein, 2005). On the other hand, studies indicated that assisting students with their homework is negatively related to achievement (Lee \& Bowen, 2006), as children do not develop self-regulatory strategies by themselves.

Nunez et al. (2015) examined the relationship between perceived parental homework involvement, student homework behaviors and student academic achievement. The data about students at elementary school, junior high school and the high school confirmed that student homework behaviors, perceived parental homework involvement and academic achievement are significantly related. However, the relationship between perceived parental involvement and academic achievement is stronger in junior high and high school than in elementary school. In the case of secondary education, Karbach et al. (2013) have found that parental control has negative relations with academic achievement. Orkin et al. (2017) analyzed the relationship of students' self-efficacy, test anxiety and parental involvement towards learning, strategy and achievement in Korean middle school mathematics. Results showed that students' academic self-efficacy had the greatest effect on learning strategy and academic achievement, suggesting that educators should increase students' academic self-efficacy, promote parental academic involvement and decrease test anxiety in order to improve learning strengths and academic achievements. None of the results was related to informal and non-formal learning processes which were activated during the recent pandemic. We supposed that parental role changes concerning the students' homework in the case of using the e-learning teaching processes.

\subsection{Teaching and learning processes through the e-learning framework}

We always underline that education has to develop appropriate mechanisms to adapt innovative teaching approaches in order to be consistent with the recent changes (Demosthenous et al., 2020). Many studies examined the role of the teaching processes in formal educational settings, while children spend the most time of their school life age out of the school boundaries where informal and nonformal learning has predominant role (Panaoura, 2017). E-learning involves the acquisition of knowledge and skills by using electronic technologies and it enables us to learn anywhere and anytime irrespective of the location (Mohammed et al., 2017). In e-learning situation students can interact directly with the learning content which is presented by different ways (document, video, audio, etc.). The interaction can take place by using a variety of internet-based synchronous and asynchronous activities. In e-learning teaching there is a requirement to have most of the course mathematics available from the beginning of the course, which is not required in the same level at the face to face teaching (She et al., 2019).

Many studies examined the differentiation at the teacher's and student's role as the main participants of the learning process (Palloff \& Pratt, 2001). Coppola et al. (2002) identified specific aspects of teacher's role: cognitive, affective and managerial. During the online processes instructor has to pose the issues for the discussion, to allocate the time, to pose the rules, to ensure a friendly environment for communication and to provide instructional design 
for interactive technologies. An important distinction between the online activities is based on the extent to which the activity is synchronous or asynchronous. In the first case, the instruction occurs in real time, while in the second case there is a time lag between the presentation of instructional stimuli and student responses. In order to engage students in interesting and attractive activities through the online environment it is recommended that consideration is given to the type and variety of the learning activities. Students can use variety of choices for their learning and they are able to take more responsibility to their learning (Zayapragassarazam, 2020). In order to equip teachers with tools to use the relevant tools "a conceptual redefinition of the teachers' roles, a well-designed training and ongoing support systems for both students and teachers" (Guri-Rosenblit, 2018), are necessary. As it is obvious in usual education circumstances the role of teachers and students are supposed to concentrate on how to improve the teaching and learning processes, while the parental involvement is examined as an important factor. The present study concentrated on the third aspect of the learning process which has not been examined yet, the parents. It examines their beliefs on their parental role concerning the learning under the special circumstances during the recent pandemic.

\subsection{The alternative teaching and learning processes during the pandemic of COVID-19}

Reimers et al. (2020) published through Organization for Economic Cooperation and Development (OECD) the text "Supporting the continuation of teaching and learning during the COVID-19 pandemic", according to which for teachers the pandemic is a challenge, while the education leaders have to design process and implement adaptive responses to the emerging challenges during and probably after the pandemic. The first cross-national survey was conducted between the $18^{\text {th }}$ and $27^{\text {th }}$ of March 2020 in order to assess educational needs and priorities. Kim and Padilla (2020) indicated that despite having a baseline level of access to technology, students and parents faced significant barriers on having adequate access to technology. Additionally Huang et al. (2020) published a handbook on facilitating flexible learning during educational disruption, by presenting the Chinese experience. Gimenez-Dasi et al. (2020) indicated that children in primary education obtained lower scores in dimensions related to their willingness to study.

Teachers' and parents' role changed dramatically during the pandemic of the coronavirus COVID-19. In the case of Cyprus, schools were closed for more than 2 months. Teachers were asked by the Ministry of Education to implement distance learning processes by using synchronous or asynchronous methods. For many days there was a confusion, as they were asked to learn and use distance learning tools or tools for communication by themselves without any centrally organised training. They had to adjust themselves in alternative for them teaching processes and provide the appropriate information to students and parents. As part of the whole process teachers sent homework to the parents and asked them to supervise their children in order to complete it. In other cases parents were asked to create passwords appropriate to login at different online tools for communication (viber, skype, Teams, google classroom, etc).

Parental involvement with homework may vary depending on the subject (Silinskas \& Kikas, 2019). The present study concentrates on math homework because many children face difficulties and encounter obstacles in maths (Kikas \& Magi, 2017) and in Cyprus it is referred at the Curriculum as one of the two most significant subjects (the other one is the learning of Greek Language), for which the students' achievements are low, according to the results of international competitions (such as Programme for International Student Assessment (PISA) and Trends in International Mathematics and Science Study (TIMSS)).

\section{Methodology}

In the beginning of the school, year 2019-2020, a questionnaire was constructed in order to examine parents' beliefs and self-efficacy beliefs about their role during the children's homework in mathematics in particular and more general about their involvement on their children's school life. The questionnaire consisted of 35 items posed by using a Likert type scale $(1=$ totally disagree, $5=$ totally agree). Indicative items were: a) I spend time to provide feedback on my child's homework, b) I ask my child to present me any new knowledge he/she acquires at school, c) I know how to encourage my child to overcome any difficulties in mathematics, d) I choose for my child board games or computer games which improve the development of mathematical thinking, e) The success in mathematics depends on child's effort, f) Parents can contribute on their children's academic success.

The questionnaire was administered at the first phase of the study to 582 parents (369 primary and 213 secondary 
education). The second phase of the study was decided to be implemented during the recent pandemic (on May 2020). The present study used the data of the 422 parents who had taken part at both phases of the study. It seemed that 305 of the parents had a child at primary education and 117 at secondary education. In that case, from each family only one of the parents completed the questionnaire which was sent to them by e-mail or through a Facebook page where it was uploaded (they had to use a platform in order to complete it online). In the case of primary education 265 mothers completed the questionnaires $(80.5 \%)$ and 64 fathers $(19.5 \%)$, while the respective numbers in the case of secondary education were 136 mothers (63.9\%) and 77 fathers (36.1\%).

A number of individual interviews were conducted by a sample of parents. Those qualitative data will be analysed as a part of a different study. At the present paper we used only few of their responses, as indicative "diamonds" in order to interpret some of the results that had been found based on the quantitative analyses. In order to examine the two main research questions, the following up statistical analyses were conducted: Exploratory factor analysis of the items was used in order to identify the cluster of the parents' beliefs and self-efficacy beliefs about their role related to their children's learning processes. The mean scores of the identified factors were used in order to compare their beliefs and self-efficacy beliefs about their involvement in learning before and after the pandemic (research question 1). Then t-test mean comparison was used in order to identify parents' differences in respect to their sex and their children's level of education (research question 2).

\section{Results}

Firstly, exploratory factor analysis was conducted. The principal component analysis of students' responses to the items of the questionnaire at the first measurement revealed six factors $(\mathrm{KMO}=0.934, \mathrm{p}<0.01)$ with eigenvalues greater than 1 . The mean score for each dimension was estimated by calculating the average of the items that comprised each factor. Cronbach's alpha coefficients for each factor were the following: F1: 0.87, F2:0.81, F3: 0.76, F4: 0.80, F5: 0.77 and F6: 0.78 .

After the content analysis of the items of each factor we found that the first factor corresponded to parents' beliefs about children's homework in general $\left(\mathrm{F} 1=\mathrm{F}_{\mathrm{GH}}\right)$. The items of the second factor expressed their respective beliefs about children's homework in the case of mathematics $\left(\mathrm{F} 2=\mathrm{F}_{\mathrm{BM}}\right)$. The third factor represented their interest in respect to their involvement on the school activities $\left(\mathrm{F} 3=\mathrm{F}_{\mathrm{I}}\right)$, while the fourth factor represented their self-efficacy beliefs on designing and using non-formal learning activities (daily activities) appropriate for the age of their children $\left(\mathrm{F} 4=\mathrm{F}_{\mathrm{SEBA}}\right)$. The fifth factor corresponded to parents' self-efficacy beliefs about choosing appropriate everyday games (online or conventional) which can be characterized as pedagogical and relevant to the expected learning processes ( $\left.\mathrm{F} 5=\mathrm{F}_{\mathrm{SEBG}}\right)$. Finally, the sixth factor represented their beliefs about the value of extra activities in mathematics which are related with national competitions, Olympiads etc $\left(\mathrm{F} 6=\mathrm{F}_{\mathrm{BEA}}\right)$. In the case of mathematics at Cyprus, students are able to voluntarily take parts into three main competitions: a) the kangaroo by the Thales foundation (multiple choice competition), b) the pancyprian competition on mathematics (four difficult mathematical problems have to be solved) and c) the pancyprian Olympiad (multiple choice competition).

The mean parents' self-report rating of the whole sample at the six factors at the initial measurement was the following in each case: $\mathrm{F}_{\mathrm{GH}}=3.18, \mathrm{~F}_{\mathrm{BM}}=3.07, \mathrm{~F}_{\mathrm{I}}=2.80, \mathrm{~F}_{\mathrm{SEBA}}=3.08, \mathrm{~F}_{\mathrm{SEBG}}=3.42, \mathrm{~F}_{\mathrm{BEA}}=2.27$. The respective means at the second measurement were in each case: $\mathrm{F}_{\mathrm{GH}}=3.58, \mathrm{~F}_{\mathrm{BM}}=3.52, \mathrm{~F}_{\mathrm{I}}=2.72, \mathrm{~F}_{\mathrm{SEBA}}=2.79, \mathrm{~F}_{\mathrm{SEBG}}=3.40, \mathrm{~F}_{\mathrm{BEA}}=$ 2.17. As it is obvious their beliefs about the role in their children's homework in general $\left(\mathrm{F}_{\mathrm{GH}}\right)$ and in the case of mathematics in particular $\left(\mathrm{F}_{\mathrm{BM}}\right)$ were increased. However, their interest about the school activities which were taken place in conventional conditions was reduced $\left(\mathrm{F}_{\mathrm{I}}\right)$. The other three factors were related with informal and non-formal learning processes and parents' self-efficacy beliefs on choosing the appropriate activities for their children. It seems that their self-efficacy beliefs were reduced especially in the case of choosing everyday activities $\left(\mathrm{F}_{\mathrm{SEBA}}\right)$ and games with pedagogical characteristics $\left(\mathrm{F}_{\mathrm{SEBG}}\right)$. Probably their recent experiences with the activities which were designed and organised by the teachers increased their uncertainty on the activities they designed for their children and mainly the suitability of those activities. At the same time they had understood their role concerning the strengths and limitations of their children due to their involvement with their homework. A mother at primary education mentioned that "I understood that my son needed my contribution in order to organize his time allocation to complete his homework", while a father at secondary education mentioned that "Although my daughter has high grades, I understand that she is 
lack of knowledge concerning general social issues in few cases. Previously, I did not have the opportunity to discuss those types of issues with her." In respect to the daily activities, a mother said that "I used to choose pedagogical games for my daughter, I played chess with her; however now I wonder whether it would be better to ask for teacher's contribution on choosing the games, as I had seen that teachers use excellent ideas which activate children's motivation".

In general, parents had negative beliefs about their role in working with their children on extra activities such as preparing them for competitions or Olympiads. They seemed to believe that teachers have to organize those types of activities only for the students who have "the talent" or very high performance in mathematics. A mother claimed that "I used to prepare my son for the kangaroo competition in Greek language and in Mathematics. I prepared him since two years ago for the mathematics Olympiad after his teacher's encouragement. He did not succeed in gaining any prize and I understand that probably I am not the suitable person to prepare him. So, now I just print the previous competitions tasks for him using website. I am not able to contribute in any other way." A father in primary education claimed that "our children are so tired by the difficult situations during the pandemic, so that I do not believe that we have to ask them to do anything extra than their homework. Unfortunately teachers sent us so many exercises and activities that children were tired by work alone. The lack of communication and social relations with their friends were exhaustive for them".

We had examined the factors' means in the case parents who had at the initial measurement a child at primary education in comparison to those who had a child in secondary education in order to examine whether there are differences according in the level of education. Table 1 presents the respective parents' self-report rating at the six factors. At it is obvious the means were higher in the case of primary education than secondary education.

Table 1. Parents' at primary and secondary education factor means at the initial measurement

\begin{tabular}{ccc}
\hline Factor & Primary education & Secondary education \\
\hline $\mathrm{F}_{\mathrm{GH}}$ & 3.68 & 1.72 \\
$\mathrm{~F}_{\mathrm{BM}}$ & 3.52 & 1.58 \\
$\mathrm{~F}_{\mathrm{I}}$ & 2.93 & 1.79 \\
$\mathrm{~F}_{\mathrm{SEBA}}$ & 3.37 & 1.91 \\
$\mathrm{~F}_{\mathrm{SEBG}}$ & 3.65 & 1.70 \\
$\mathrm{~F}_{\mathrm{BEA}}$ & 2.45 & 2.22 \\
\hline
\end{tabular}

At Table 2 we present the respective parents' self-report rating at the six factors in the case of the second measurement, after the experience of the pandemic.

Table 2. Parents' at primary and secondary education factor means at the second measurement

\begin{tabular}{ccc}
\hline Factor & Primary education & Secondary education \\
\hline$F_{\mathrm{GH}}$ & 3.28 & 1.98 \\
$\mathrm{~F}_{\mathrm{BM}}$ & 3.27 & 1.67 \\
$\mathrm{~F}_{\mathrm{I}}$ & 2.80 & 1.96 \\
$\mathrm{~F}_{\mathrm{SEBA}}$ & 3.28 & 2.32 \\
$\mathrm{~F}_{\mathrm{SEBG}}$ & 3.60 & 1.87 \\
$\mathrm{~F}_{\mathrm{BEA}}$ & 2.47 & 1.92 \\
\hline
\end{tabular}

As it is obvious the means were higher in the case of primary education at both measurements. There was a decrease in the case of $\mathrm{F}_{\mathrm{GH}}$ and $\mathrm{F}_{\mathrm{BM}}$, while there were not any significant changes in respect to their self-efficacy beliefs. 
On the contrary, in the case of secondary education in all cases, except the sixth factor $\left(\mathrm{F}_{\mathrm{BEA}}\right)$ their beliefs and selfefficacy beliefs were increased although there were lower than in primary education. It seems that parents at secondary education were obliged to be involved with their children's homework. A future study can examine whether there are any differences in the case of the lower grades in secondary education in comparison to the higher grades. In primary education, parents received their children's passwords, instructions for homework, etc., through the e-mails and announcements by the school at their mobile phones (due to legal issues), while in the secondary education there was a direct communication between teachers and young students.

We had examined whether there were statistically significant differences between fathers and mothers in respect their beliefs and self-efficacy beliefs concerning their role for their children's homework at the initial measurement. T-test analysis $(\mathrm{p}<0.05)$ in the case of primary indicated that there were statistically significant differences at all the factors. The means are presented at Table 3 .

Table 3. Parents' self-report rating means at the six factors in respect to their sex

\begin{tabular}{ccc}
\hline Factor & Father & Mother \\
\hline $\mathrm{F}_{\mathrm{GH}}$ & 3.60 & 3.24 \\
$\mathrm{~F}_{\mathrm{BM}}$ & 2.95 & 3.31 \\
$\mathrm{~F}_{\mathrm{I}}$ & 2.20 & 2.89 \\
$\mathrm{~F}_{\text {SEBA }}$ & 3.80 & 3.20 \\
$\mathrm{~F}_{\mathrm{SEBG}}$ & 3.15 & 3.67 \\
$\mathrm{~F}_{\text {BEA }}$ & 3.19 & 3.51 \\
\hline
\end{tabular}

As it is obvious in almost all cases mothers had more positive beliefs and self-efficacy beliefs about their involvement role at their children's homework. Only in the case of their self-efficacy beliefs about the everyday nonformal activities which were related to the school activities they seemed to feel less sufficient than the fathers. They were more acquainted with the homework activities derived by teachers and as a mother said "I cannot be sure about the relevance of the activities I asked my children to do. I am not a teacher and my criterion is mainly their happiness and to have creative time, rather than doing learning activities all the time". Undoubtedly parents do not know and do not have to know the role of everyday activities as part of non-formal learning and they have the misunderstanding that the school purposes are related only with knowledge.

In the case of the parents with children at the secondary education there were statistically significant differences ( $p$ $<0.05)$ only in the case of the $3^{\text {rd }}$ and the $5^{\text {th }}$ factor $\left(\mathrm{F}_{\mathrm{I}}\right.$ and $\left.\mathrm{F}_{\mathrm{SEBG}}\right)$. Specifically the mean of the $3^{\text {rd }}$ factor (interest about the involvement in school activities) in the case of father was 1.59 and in the case of mother was 1.86 . Both of them were low. In the case of the $5^{\text {th }}$ factor (self-beliefs about choosing relevant games) the father's mean was 1.98 and the respective mother's was 1.33 .

\section{Discussion}

Government, teachers, academics of pedagogical departments and parents should closely collaborate together to ensure high quality learning content, diverse and appropriate learning activities and effective learning outcomes for students. In conventional circumstances, many studies concentrate on the examination of the basic factors and the respective interrelations among those factors. In non-conventional circumstances, the participants' role change and the relations or interrelations are differentiated. The COVID-19 pandemic has made changes in various sectors of life including education (Sulisworo et al., 2020). Teachers, students and parents had to face barriers and difficulties in order to adjust themselves at using e-learning processes (Schleicher, 2020).

Parents through their everyday activities with their children use consciously or unconsciously non-formal learning 
processes. When they have to be involved with their children's homework they activate informal teaching processes which can be appropriate or not. In order to be relevant and suitable to their child's personal characteristics they need the teacher's guidance and support. The present study indicated that the parents' lack of confidence or their low self-efficacy beliefs on using the relevant activities related to the formal or informal teaching were enhanced during the pandemic where they had to understand the differentiation of their role. At the same time, the present study confirmed previous studies which indicated that mothers spent more time on their children's homework. In a similar study among parents with school-aged children in the UK, 64\% of mothers reported doing some homeschooling activities in comparison to $49 \%$ of fathers. The average time spent daily on homeschooling was 2.2 hours, while mothers spent 1.5 hours more than fathers (Villadsen et al., 2020). Apparently, it is a is apparently a serious social issue which remains open for further examination and actions.

The major educational aims today, as presented at different curriculum are flexible construction, self-regulated learning, respect for differentiation, open resources and technological support (Huanj et al., 2020). The lockdown in response to COVID-19 has interrupted conventional schooling and although the educational community has made concerted efforts to maintain learning continuity, children had to rely more on their own resources to continue learning remotely. Teachers had to adapt to new pedagogical modes of delivery of teaching for which they may not have been trained and parents had to face news challenges for which were not prepared. However, the recent experience of the international pandemic indicated that technological tools, equipment, knowledge and experiences were not adequate in order to enable the transition from the typical teaching processes to e-learning processes. Particularly parents faced the challenge of being both parents and teachers at the same time (Azubuike \& Aina, 2020). Undoubtedly the parental involvement was necessary in the case of primary education and probably it was a major factor that could be used further in order to face and overcome the difficulties. The present study underlined the necessity to prepare parents for their role and the improvement of the system preparation in order to avoid asking them to take the role of teachers.

According to the World Economic Forum (2020) many issues had been raised concerning the teaching practices during the recent pandemic: we need to reduce screen time and modify the curriculum accordingly. We believe that many other issues will be revealed through the recent studies which were developed in order to examine aspects of the consequences of the pandemic. For example the e-learning methods need to be used differently based on different students' learning styles, cognitive styles, inter-individual characteristics.

The present study indicated the differentiation of parents' roles. Anxiety, uncertainty, more negative beliefs and self-efficacy beliefs about their contribution on their children's learning were obvious. By having in mind that "the only way to prevent Covid-19 from deepening inequality for an entire generation of children is to equip families to support learning at home" (Seale, 2020), the present study did not examine issues of equality in respect to the home technological tools. However, it examined the parents' beliefs and self-efficacy beliefs about their involvement in their children's learning performance in normal situation and in the case of unexpected situations. It seems that during the pandemic they had to play a role for which they were not prepared and teachers were not able to guide them adequately. However, through those experiences, they were obliged to realize their role, their strengths and limitations about their children's learning. This is extremely important in early grades in which children's learning requires frequent adult facilitation. Although the present study did not examine the equality of students' opportunities based on their parents' knowledge, experiences, economic status, we had identified their uncertainty about the differentiation of their role and their need to understand how they could be co-operators with teachers at their children's learning process.

The present study revealed parents' beliefs and self-efficacy beliefs before and after the pandemic. It seems that they understood the influence of their contribution on their children's academic performance and they realized the lack of knowledge on how to develop their children's thinking through non formal daily activities. Based on the specific opportunity we can organize relevant training for teachers at both educational levels (primary and secondary education) in order to prepare accordingly parents for their role at the development of children's learning strategies in general and in the case of mathematics in particular which are useful for conventional and e-learning processes. Our study presents the parents' willingness to support their children's learning; the main issue is how to support them so that they can turn the willingness into action even under unexpected surrounding social situations. Many educational systems aim to study further the flexible transmission from conventional to e-learning teaching processes. Future studies can concentrate further on parents' role concerning their involvement in their children's learning by taking into consideration homework and daily activities. 


\section{References}

Azubuike, O., \& Aina, B. (2020). How parents are supporting their children's learning during the Covid-19 pandemic in Nigeria.

Boonka, L., Gijselaersa, H., Ritzenb, H., \& Brand-Gruwela, S. (2018). A review of the relationship between parental involvement indicators and academic achievement. Educational Research Review, 24, 10-30. https://doi.org/10.1016/ j.edurev.2018.02.001

Cai, J. (2004). Why do US and Chinese students think differently in mathematical problem solving? Exploring the impact of early algebra learning and teachers' beliefs. Journal of Mathematical Behavior, 23(2), 135-167. https://doi. org/10.1016/j.jmathb.2004.03.004

Demosthenous, G., Panaoura, A., \& Eteokleous, N. (2020). The use of collaborative assignment in online learning environment: The case of higher education. International Journal of Technology in Education and Science, 4(2), 108117.

Fernandez-Alonso, R., Alvarez-Diazl, M., Woitschach, P., \& Suarez-Alvarez, J. (2017). Parental involvement and academic performance: Less control and more communication. Psicothema, 29(4), 453-461.

Gimenez-Dasi, M., Quintanilla, L., Lucas-Molina, B., \& Sarrinento-Henrique, R. (2020). Six weeks of confinement psychological effects on a sample of children in early childhood. Frontiers in Psychology, 11. https://doi.org/10.3389/ fpsyg.2020.590463

Gomes, S. D. (2015). Parental involvement: The missing link in academic performance, socialization and coping behavior of students at St. Louis high school in Natore, Bangladesh. International Conference on Language, Education, Humanity, Innovation. 157-167.

Guri-Rosenblit, S. (2018). E-teaching in higher education: An essential prerequisite for e-learning. Journal of New Approaches in Educational Research, 7(2), 93-97. https://doi:10.7821/naer.2018.7.298

Huang, R. H., Liu, D. J., Tlili, A., Yang, J. F., Wang, H. H., Chang,T. W., \& Zhuang, R. H. (2020). Handbook on facilitating flexible learning during educational disruption: The chinese experience in maintaining undisrupted learning in COVID-19 outbreak. Beijing: Smart Learning Institute of Beijing Normal University.

Karbach, J., Gottschling, J., Spengler, M., Hegewald, K., \& Spinath, F. (2013). Parental involvement and general cognitive ability as predictors of domain-specific academic achievement in early adolescence. Learning and Instruction, 23, 43-51. https://doi.org/10.1016/j.learninstruc.2012.09.004

Kikas, E., \& Mägi, K. (2017). Does self-efficacy mediate the effect of primary school teachers' emotional support on learning behavior and academic skills? Journal of Early Adolescence, 37(5), 696-730. https://doi. org/10.1177/0272431615624567

Lee, J., \& Bowen, N. (2006). Parental involvement, cultural capital, and the achievement gap among elementary school children. American Educational Research Journal, 43(2), 193-218. https://doi.org/10.3102/00028312043002193

Mohammed, A., Kumar, S., Saleh, B., \& Shuaibu, A. (2017). E-learning: A tool for enhancing teaching and learning in educational institutes. International Journal of Computer Science and Information Technology, 8(2), 217-221.

Nguon, S. (2012). Parental involvement and students' achievement in Cambodia: Focusing on parental resourcing of public schooling. International Journal of Educational Research, 53, 213-224. https://doi.org/10.1016/j.ijer. 2012.03.011

Nunez, J. C., Suarez, N., Rosario, P., Vallejo, G., Valle, A., \& Epstein, J. L. (2015). Relationships between perceived parental involvement in homework, student homework behaviors, and academic achievement: Differences among elementary, junior high and high school students. Metacognition and Learning, 10(3), 375-406. https://doi.org/ 10.1016/j.cedpsych.2015.08.001

Olmstead, C. (2013). Using technology to increase parent involvement in schools. TechTrends, 57(6), 28-37. https://doi. org/10.1007/s11528-013-0699-0

Orkin, M., May, S., \& Wolf, M. (2017). How parental support during homework contributes to helpless behaviors among struggling readers. Reading Psychology, 27, 506-541. https://doi.org/10.1080/02702711.2017.1299822

Palloff, R. M., \& Pratt, K. (2001). Lessons from the cyberspace classroom: The realities of online teaching. San Francisco: Jossey-Bass.

Panaoura, A., Demosthenous, G., Eteokleous, N., \& Baldukas, A. (2017). The informal parental education and the non-formal children's learning: the development of strategies for perseverance in mathematical problem solving. $7^{\text {th }}$ conference of the Greek Association for the Teaching of Mathematics, 640-649.

Panaoura, A. (2017). Parental involvement in developing students' perseverance in solving mathematical problems through the use of social media. International Journal of Technology in Education and Science, 1(1), 36-47.

Patall, E., Cooper, H., \& Robinson, J. (2008). Parental involvement in Homework: A research synthesis. Review of Edu- 
cational Research, 78(4), 1039-1101.

Reimers, F., Schleider, A. Saavedra, J., \& Tuominen, S. (2020). Supporting the continuation of teaching and learning during the COVID-19 pandemic. Annotated resources for online learning. OECD. https://globaled.gse.harvard.edu/ files/geii/files/supporting-the-continuation-of-teaching-and-learning-during-the-covid-19-pandemic.pdf

Rosario, P., Nunez, J., Vallejo, G., Nunes, T., Cunha, J., Fuentes, S., \& Valle, A. (2018). Homework purposes, homework behaviors, and academic achievement. Examining the mediating role of students' perceived homework quality. Contemporary Educational Psychology, 53, 168-180. https://doi.org/10.1016/j.cedpsych.2018.04.001

Schleicher, A. (2020). The impact of covid-19 on education. Insights from education at a glance. OECD.

Seale, C. (2020). Parent involvement has always mattered. Will the covid-19 pandemic finally make this the new normal in K-12 education? https://www. Forbes.com/sites/colinseale/2020/05/19

She, C. N., Farrell, O., Brunton, J., Costello, E., Donlon, E., Trevaskis, S., \& Eccles, S. (2019) Teaching online is different: critical perspectives from the literature. Dublin: Dublin City University. https://doi.org/10.5281/zenodo.3479402

Sheldon, S., \& Epstein, J. (2005). Involvement counts: Family and community partnerships and mathematics achievement. The Journal of Educational Research, 98(4), 196-207. https://doi.org/10.3200/JOER.98.4.196-207

Sibley, E., \& Dearing, E. (2014). Family educational involvement and child achievement in early elementary school for American-born and immigrant families. Psychology in the Schools, 51(8). https://doi.org/10.1002/pits.21784

Silinskas, G., \& Kikas, E. (2019). Parental involvement in math homework: Links to children's performance and motivation. Scandinavian Journal of Educational Research, 63(1), 17-37.

Sulisworo, D., Fitrianawati, M., Maryani, I., Hidayat, S., Augusta, E., \& Saputri, W. (2020). Students' self-regulated learning (SRL) profile dataset measured during Covid-19 mitigation in Yoyuakarta Indonesia. Data in Brief, 33, 106422. https://doi.org/10.1016/j.dib.2020.106422

UNESCO (2020). COVID-19 impact on education. https://en.unesco.org/covid19/educationresponse.

Veas, A., Castejon, J., Minano, P., \& Gilar-Corb, R. (2018). Relationship between parent involvement and academic achievement through metacognitive strategies: A multiple multilevel mediation analysis. British Journal of Educational Psychology, 89(2), 393-411.

Villadsen, A., Conti, G., \& Fitzsimons, E. (2020). Parental involvement in home schooling and developmental play during lockdown. UCL report. https://cls.ucl.ac.uk/wp-content/uploads/2017/02/Parental-involvement-in-homeschooling-and-developmental-play-during-lockdown-initial-findings-from-COVID-19-survey.pdf

Zayapragassarazan Z. (2020). COVID-19: Strategies for online engagement of remote FGH000Research, 9, 246. https:// doi.org/10.7490/FGH000research.1117835.1

World Economic Forum. (2020). What lessons from the coronavirus pandemic will shape the future of education? https://www.weforum.org/agenda/2020/05/covid19-lockdown-future-education/ 